\title{
Laterality differences in sensitivity to line orientation as a function of adaptation duration
}

\author{
B. EBO TEI and DEAN H. OWEN \\ Ohio State University, Columbus, Ohio 43210
}

\begin{abstract}
Since available evidence indicates that the two cerebral hemispheres are differentially sensitive to different types of stimulus information, and that they also utilize different strategies in processing information, is it possible that the two hemispheres are differentially sensitive to adaptation? Three groups of four subjects each were adapted to black and white gratings using three adapting durations: $500,1,000$, and 5,000 msec. Immediately following adaptation, a test grating was presented in either the left or right visual field. The task of the subject was to determine whether the lines of the adapting and test gratings had the same orientation or not. Analysis showed that in the 5,000 -msec and $1,000-\mathrm{msec}$ conditions, more errors occurred with left visual field presentations, responses to left visual field presentations took longer, and a bias-free measure showed that subjects were more sensitive to right visual field presentations. For the 500-msec group, there were no apparent differences between left and right visual fields presentations. The results indicate differential effects of adaptation on the two hemispheres, suggesting sensitivity differences between the two halves of the brain.
\end{abstract}

Laterality differences (LD) in visual perception usually refer to the differences in the accuracy of recall or recognition favoring information presented in one visual hemifield over that in the other hemifield. Various interpretations of LD have been proposed and among these is the cerebral dominance explanation.

Since the early observations of Broca and Dax in the 1860's (see Milner, 1971) it has been known that the brain serves different cognitive functions. It has been known that, in general, the behavioral effects of a unilateral brain lesion vary both with hemisphere and site of the lesion within the hemisphere.

More recently, definitive work has been done with commissurotomized (split-brain) patients (Levy, Trevarthen, \& Sperry, 1972; Nebes, 1971, 1972, 1974; Sperry, 1968; Sperry \& Gazzaniga, 1967; Zaidel \& Sperry, 1973). The evidence suggests that by restricting input to the left hemisphere, the verbal capacities demonstrated are equivalent to those elicited from the uncommissurotomized subject under more conventional testing. At the same time, it has been consistently demonstrated that the right hemisphere is far superior to the left hemisphere in tasks involving the recognition and construction of spatial or partwhole relations. The thrust of these studies suggests

This paper is based on a dissertation presented by the first author in partial fulfilment of the requirements for the PhD degree at the Ohio State University, Columbus, Ohio. B. Ebo Tei is now at the University of Arkansas at Pine Bluff. Requests for reprints or inquiries should be sent to B. Ebo Tei, Psychology Department, University of Arkansas at Pine Bluff, Pine Bluff, Arkansas 71601 . that the two hemispheres utilize different perceptual or information-processing approaches. The evidence also suggests that if a task, whether verbal or nonverbal, requires a verbal transformation of the input, then the left hemisphere controls execution; however, if the nature of the task is perceptual and requires no verbal transformation of the input, it is the right hemisphere that controls execution.

The question, then, is: What may be the basis of the functional difference between the two hemispheres? The answer to this question will by no means be simple. However, recent electrophysiological studies (e.g., Campbell, Cleland, Cooper, \& Enroth-Cugell, 1968; Hubel \& Wiesel, 1962, 1965, 1968) and psychophysical studies (e.g., Blakemore \& Campbell, 1969; Campbell \& Kulikowski, 1966; Fidell, 1970; Gilinsky \& Cohen, 1972; McCollough, 1965; Weinstein, 1969) may provide a partial insight into this functional asymmetry of the hemispheres. These studies indicate that there are orientation-specific contour "detectors" present in the human visual system, and the hemispheric functional asymmetry may have something to do with the properties of feature detectors.

The problem of interest here is whether orientationspecific detectors (OSDs) operate differently in the two hemispheres. One way to answer this question is through the technique of selective adaptation. Arguing by analogy from the effects of light and color adaptation, it should be expected that prolonged viewing of a form exhibiting a particular visual feature should selectively adapt the detecting mechanism for that feature. This would tend to render the visual system less sensitive to that feature in subsequent pat- 
terned stimulation. This seems to be the case in studies of adaptation to line gratings. An orientationspecific neural unit exhibits a decline in response rate with prolonged stimulation. After such stimulation, the unit is in a state of reduced sensitivity from which it recovers over time, gradually regaining normal sensitivity.

It could reasonably be assumed that in studies of selective adaptation to line gratings, the nature of the task is perceptual and does not involve any verbal transformation of the input. This would seem to suggest that the OSDs in the right hemisphere will control or greatly influence the execution of such tasks. This suggestion follows from the overwhelming evidence that the two hemispheres differ markedly in tasks involving spatial and part-whole relations, with the right hemisphere being superior. Furthermore, clinical data (e.g., De Renzi, Faglioni, \& Scotti, 1971; Warrington \& Rabin, 1970) have indicated that performance on a task involving the discrimination or the judgment of line orientation is impaired after right-hemisphere lesions, but not after left.

It follows, then, that since the hypothesized effect of selective adaptation to line gratings is to temporarily depress the sensitivity of the OSDs, it is the right hemisphere that will be affected most. From this, it also follows that in a typical LD setup, judgments to test gratings presented in the left visual field (LVF) should be affected more by the prior selective adaptation than judgments to test gratings presented in the right visual field (RVF), since it is the right hemisphere that loses sensitivity during the adaptation period.

The reasoning here is that during the initial adaptation period, since only the OSDs in the right hemisphere are being utilized and are the only ones exerting control, when the test grating appears in the LVF (because the OSDs in the right hemisphere have lost sensitivity), the subject will be forced to guess from the little information that is available.

A further assumption is that when the right hemisphere loses sensitivity during adaptation, it also temporarily loses the control that it normally exerts for the performance of tasks of this nature-it is temporarily "powerless." At the same time, since the OSDs in the left hemisphere still possess their sensitivity (because they have not been affected as much by the adaptation), and because the right hemisphere is exerting less inhibitory control, the left-hemisphere OSDs that do not normally function (as a result of the inhibition from the right hemisphere) are now able to function. When the test grating appears in the RVF, the judgments should be least affected by the initial adaptation.

In summary, the hypothesis being advanced here, then, is that since the right hemisphere plays a greater role in the judgment and discrimination of line orientations, the OSDs in the right hemisphere should be affected more by selective adaptation to line orienta- tions. It follows, then, that in a typical LD experiment involving selective adaptation, judgments to test gratings in LVF presentations should be more adversely affected than judgments to test gratings presented in the RVF.

\section{Method}

Subjects. Twelve right-handed male undergraduate psychology students took part in the study. Subjects were required to have 20/20 vision, with or without corrective lenses.

Material. The adapting and test gratings were constructed using FORMATT No. 7062 black and white grating, and black Chartpak No. 6201M pressure-sensitive tape. Both the black and the white stripes were $1.6 \mathrm{~mm}$ in width so that the density of the lines of the gratings was $50 \%$. The shape of the gratings was circular with the diameter of the adapting grating being $20.4 \mathrm{~cm}$ and that of the test grating being $5.1 \mathrm{~cm}$. The gratings were photographed and made into $2 \times 2$ in. $(5.1 \times 5.1 \mathrm{~cm})$ transparencies. Twelve adapting gratings and 12 test gratings were produced by changing the orientation of lines in the gratings in 15-deg intervals from 0 to $165 \mathrm{deg}$. When projected on the screen, the adapting grating subtended a visual angle of $8 \mathrm{deg}$ with the frequency of the lines being 4 cycles $/ \mathrm{deg}$. The test grating subtended a visual angle of $2 \mathrm{deg} 5 \mathrm{~min}$, with the same spatial frequency as the adapting grating. The luminance of both the adapting and test field was $.3 \mathrm{~cd} / \mathrm{m}^{2}$.

Apparatus and Procedure. The study tested three adapting durations: 500, 1,000, and 5,000 msec. Each subject was assigned to only one of these three conditions. There were four subjects in each condition, and each was tested for four separate 1-h sessions. There were 10 practice trials at the beginning of the first session. The slides were back-projected onto a screen using two Kodak carousel slide projectors containing gas tube lamps. One of the slide projectors was used exclusively for the 12 adapting gratings, and the second was for the 24 test gratings (12 gratings for the left visual field and 12 for the right visual field). The projectors were powered by a two-channel Scientific Prototype tachistoscope power source interfaced with a Hunter Model 1516 timer. A third projector displayed a fixation point.

At the beginning of each session, the subject was seated in front of the screen in a cubicle. The position of the chair was such that, on the average, the distance from the center of the screen to the eyes of the subject was $38.5 \mathrm{~cm}$. The subject was allowed to dark adapt for about 4 to $5 \mathrm{~min}$ before the session began.

Following a "ready" signal from the experimenter, the subject displayed the fixation point by depressing a foot pedal. The subjects were instructed that it was imperative and an integral part of the experiment that they fixate on the spot of light in the center of the field. The fixation point stayed on for the duration of the trial.

After an interval of $500 \mathrm{msec}$ following the appearance of the fixation point, the adapting line grating appeared in the center of the visual field. The arrangement was such that the fixation point was the center of the big adapting grating. The adapting grating stayed on the screen for a duration of $500,1,000$, or $5,000 \mathrm{msec}$, depending on the experimental condition. Immediately following the exposure duration of the adapting grating, the test grating was presented for $100 \mathrm{msec}$ to either the left or right of the central fixation point. This test grating was always presented such that its edge was $3 \mathrm{deg} 52 \mathrm{~min}$ to the right or left of the fixation point. The test grating fell wholly within either the left or right half of the adapting grating.

The task of the subject was to judge whether the orientation of the lines of the adapting grating was the same as the orientation of the lines of the test grating. Half the subjects in each condition pushed a response lever to the right if the two orientations were judged to be the same; the other half pushed the lever to the left. Subjects were instructed to make these judgments as quickly and accurately as possible. A millisecond timer 
was activated at the onset of the test grating and stopped when the subject pushed the response lever to either side.

Immediately after making their same/different judgments, subjects gave ratings of their confidence in the correctness of these judgments. A rating of 3 indicated "very confident," a rating of 1 "not certain" (guessing), and a rating of 2 "moderate certainty."

The intertrial interval was about $20 \mathrm{sec}$. Each subject was tested for 528 trials, spread over the four different sessions. Each adapting orientation was paired with the test grating of the same orientation 22 times (11 presentations in the left and 11 presentations in the right visual field) and four times with each of the other test orientations (two presentations in both the right and left fields). Overall, half of the test gratings had the same orientation as the adapting grating, and the other half had a different orientation. The order of presentation was randomized with the constraint that no more than two successive repetitions of the same adapting orientation could occur.

\section{Results}

To determine whether there was any laterality effect, three summary measures were calculated for each visual field: the subject's discrimination performance or sensitivity $\left(A_{g}\right)$, the mean reaction time $(R T)$ for deciding whether the two orientations were the same or different, and the mean number of errors of judgment committed (errors combined for both "same" and "different" judgments ${ }^{1}$ ).

$\mathbf{A}_{\mathrm{g}}$ or sensitivity variable. Each subject's data were analyzed separately because different subjects can exhibit different laterality effects. For purposes of calculating the discrimination performance or sen- sitivity index $\left(A_{g}\right)$ for each subject, the trials of interest were those on which the subject said "same" given that the two orientations were the same (a hit), and those trials on which he said "same" given that the two orientations were different (a false alarm). For each confidence rating category, the frequency of correct and incorrect judgments for presentations in each visual field was computed. A computer program that uses the rating-scale procedure for generating points on the isosensitive curve (Davison \& Jagacinski, 1977) was used to generate a curve for subjects in each of the three conditions.

A two-tailed $z$ test for testing differences between proportions showed that for all subjects in the 5,000msec condition, the $A_{g}$ for right visual field (RVF) presentations was significantly larger than that for left visual field (LFV) presentations $(p<.01)$. For two of the subjects in the 1,000 -msec condition, the difference between the two areas was significant $(p<.05)$, while for the other two subjects, the difference was not significant. For all subjects in the 500 -msec condition, the two $\mathrm{A}_{\mathrm{g}}$ scores were virtually the same-there were no significant differences.

An interesting finding was that the longer the adaptation duration, the greater the differences between the two areas under the curves. In general, adaptation affected the LVF presentations more than the RVF presentations. (See Tables 1 and 2.)

Table 1

Summary Data for Each Subject Showing Area Under the Isosensitive Curve (Ag), Reaction Time (RT), and Accuracy (Proportion Correct) as a Function of Adapting Duration, Visual Field, and Same vs. Different Pairings (Pair Type)

\begin{tabular}{|c|c|c|c|c|c|c|c|}
\hline \multirow[b]{2}{*}{ Subject } & \multirow[b]{2}{*}{ Condition } & \multirow[b]{2}{*}{ Field } & \multirow[b]{2}{*}{$\mathrm{Ag}$} & \multicolumn{2}{|c|}{ RT } & \multicolumn{2}{|c|}{ Proportion Correct } \\
\hline & & & & Same & Different & Same & Different \\
\hline M.S. & 5000 & $\begin{array}{l}\text { LVF } \\
\text { RVF }\end{array}$ & $\begin{array}{l}.52 \\
.83\end{array}$ & $\begin{array}{l}1926 \\
1494\end{array}$ & $\begin{array}{l}2260 \\
1375\end{array}$ & $\begin{array}{l}.47 \\
.81\end{array}$ & $\begin{array}{l}.52 \\
.74\end{array}$ \\
\hline T.W. & 5000 & $\begin{array}{l}\text { LVF } \\
\text { RVF }\end{array}$ & $\begin{array}{l}.52 \\
.86\end{array}$ & $\begin{array}{l}1692 \\
1185\end{array}$ & $\begin{array}{l}1609 \\
1328\end{array}$ & $\begin{array}{l}.55 \\
.89\end{array}$ & $\begin{array}{l}.49 \\
.74\end{array}$ \\
\hline G.W. & 5000 & $\begin{array}{l}\text { LVF } \\
\text { RVF }\end{array}$ & $\begin{array}{l}.86 \\
.97\end{array}$ & $\begin{array}{l}1461 \\
1112\end{array}$ & $\begin{array}{r}1223 \\
837\end{array}$ & $\begin{array}{l}.61 \\
.91\end{array}$ & $\begin{array}{l}.86 \\
.93\end{array}$ \\
\hline M.W. & 5000 & $\begin{array}{l}\text { LVF } \\
\text { RVF }\end{array}$ & $\begin{array}{l}.76 \\
.93\end{array}$ & $\begin{array}{l}1476 \\
1229\end{array}$ & $\begin{array}{l}1215 \\
1132\end{array}$ & $\begin{array}{l}.63 \\
.89\end{array}$ & $\begin{array}{l}.77 \\
.87\end{array}$ \\
\hline L.S. & 1000 & $\begin{array}{l}\text { LVF } \\
\text { RVF }\end{array}$ & $\begin{array}{l}.80 \\
.89\end{array}$ & $\begin{array}{l}1012 \\
1015\end{array}$ & $\begin{array}{l}1032 \\
1003\end{array}$ & $\begin{array}{l}.59 \\
.64\end{array}$ & $\begin{array}{l}.74 \\
.89\end{array}$ \\
\hline$M \cdot W_{\cdot 2}$ & 1000 & $\begin{array}{l}\text { LVF } \\
\text { RVF }\end{array}$ & $\begin{array}{l}.85 \\
.90\end{array}$ & $\begin{array}{l}1384 \\
1286\end{array}$ & $\begin{array}{l}1373 \\
1320\end{array}$ & $\begin{array}{l}.67 \\
.84\end{array}$ & $\begin{array}{l}.79 \\
.85\end{array}$ \\
\hline B.S. & 1000 & $\begin{array}{l}\text { LVF } \\
\text { RVF }\end{array}$ & $\begin{array}{l}.90 \\
.97\end{array}$ & $\begin{array}{l}1401 \\
1053\end{array}$ & $\begin{array}{r}1058 \\
951\end{array}$ & $\begin{array}{l}.67 \\
.92\end{array}$ & $\begin{array}{l}.92 \\
.92\end{array}$ \\
\hline S.T. & 1000 & $\begin{array}{l}\text { LVF } \\
\text { RVF }\end{array}$ & $\begin{array}{l}.87 \\
.92\end{array}$ & $\begin{array}{l}1258 \\
1135\end{array}$ & $\begin{array}{l}1176 \\
1145\end{array}$ & $\begin{array}{l}.73 \\
.86\end{array}$ & $\begin{array}{l}.83 \\
.91\end{array}$ \\
\hline C.S. & 500 & $\begin{array}{l}\text { LVF } \\
\text { RVF }\end{array}$ & $\begin{array}{l}.88 \\
.94\end{array}$ & $\begin{array}{l}1181 \\
1156\end{array}$ & $\begin{array}{l}1096 \\
1077\end{array}$ & $\begin{array}{l}.60 \\
.68\end{array}$ & $\begin{array}{l}.89 \\
.95\end{array}$ \\
\hline T.H. & 500 & $\begin{array}{l}\text { LVF } \\
\text { RVF }\end{array}$ & $\begin{array}{l}.95 \\
.93\end{array}$ & $\begin{array}{l}1336 \\
1222\end{array}$ & $\begin{array}{l}1230 \\
1222\end{array}$ & $\begin{array}{l}.87 \\
.94\end{array}$ & $\begin{array}{l}.90 \\
.85\end{array}$ \\
\hline J.K. & 500 & $\begin{array}{l}\text { LVF } \\
\text { RVF }\end{array}$ & $\begin{array}{l}.86 \\
.87\end{array}$ & $\begin{array}{l}1331 \\
1248\end{array}$ & $\begin{array}{l}1179 \\
1077\end{array}$ & $\begin{array}{l}.72 \\
.67\end{array}$ & $\begin{array}{l}.81 \\
.95\end{array}$ \\
\hline C.W. & 500 & $\begin{array}{l}\text { LVF } \\
\text { RVF }\end{array}$ & $\begin{array}{l}.79 \\
.79\end{array}$ & $\begin{array}{l}1314 \\
1427\end{array}$ & $\begin{array}{r}1001 \\
961\end{array}$ & $\begin{array}{l}.70 \\
.42\end{array}$ & $\begin{array}{l}.76 \\
.98\end{array}$ \\
\hline
\end{tabular}


Table 2

Summary Results Showing Levels of Significance for Each Subject as a Function of the Three Dependent Variables

\begin{tabular}{lclll}
\hline Subject & Condition & Ag & RT & Accuracy \\
\hline M.S. & 5000 & $.01^{*}$ & $.001^{* *}$ & $.001 \dagger$ \\
T.W. & 5000 & .01 & .001 & .001 \\
G.W. & 5000 & .01 & .001 & .001 \\
M.W. 1 & 5000 & .01 & .001 & .001 \\
L.S. & 1000 & .05 & .03 & .009 \\
M.W. & 1000 & n.s. & .01 & .001 \\
B.S. & 1000 & .05 & .001 & .001 \\
S.T. & 1000 & n.s. & .001 & .001 \\
C.S. & 500 & n.s. & n.s. & n.s. \\
T.H. & 500 & n.s. & n.s. & n.s. \\
J.K. & 500 & n.s. & .001 & n.s. \\
C.W. & 500 & n.s. & n.s. & n.s. \\
\hline
\end{tabular}

Note-For all entries, $p<$ the value shown; n.s. = nonsignificant. * Area under $R V F$ curve greater than area under $L V F$ curve. **Subjects faster in $R V F$ presentations (i.e., $R V F<L V F$ ). + More errors in the LVF presentations.

Reaction time. The second dependent measure was the time taken to make the "same/different" judgments. For each subject, the mean correct RTs (on same and different pairs) to both LVF and RVF presentations were subjected to a Field (2) by Pair Type (same/different; 2) unequal- $\mathrm{N}$ analysis of variance.

For all subjects in the $5,000-\mathrm{msec}$ condition, there was a significant Field main effect $(p<.001)$. All subjects were consistently faster in making judgments to RVF presentations by at least $164 \mathrm{msec}$.

For all subjects in the 1,000 -msec condition, there was a significant main effect for Field, with $p$ values ranging from $p<.001$ to $p<.03$. For all subjects, responses to $\mathrm{RVF}$ presentations were consistently faster than responses to LVF presentations.

Of the four subjects in the 500 -msec condition, only one showed a significant main effect for Field $[F(1,412)=11.28, p<.001]$. For this subject, too, responses to RVF presentations were on the average faster by $93 \mathrm{msec}$ than responses to LVF presentations.

Error rates. The third dependent measure analyzed was the pooled error rate for same and different pairings for the LVF presentations as compared with RVF presentations. The analysis of variance showed that for all subjects in both the 5000-msec and 1,000msec conditions, there was a significant laterality effect. For both groups of subjects, there was a significantly higher error rate for presentations in the LVF ( $p<.001$ for seven of the eight subjects, and $p<.009$ for one subject in the 1,000 -msec group) than for RVF presentations. However, there was no significant difference in error rate between LVF and RVF for any subjects in the 500 -msec condition.

All three dependent measures provide evidence pointing in the same direction-that is, subjects are less sensitive to LVF presentations (as evidenced by the $A_{g}$ measure), they take much longer to make judgments on LVF presentations, and, because they are less sensitive to the LVF presentations, they also tend to make more errors of judgment in the LVF.

The second major effect relates to the adaptation effects, which are very consistent with the general trend in the literature-if subjects are adapted to a grating with lines in a specific orientation, thresholds are elevated for lines in the same orientation, or subjects take longer to respond to lines in the same orientation as those in the adapting grating.

Following the individual analysis, it was apparent that subjects in all the three conditions were exhibiting similar laterality effects. It therefore seemed appropriate to pool across subjects and examine the data as a function of the three adapting durations in terms of sensitivity $\left(A_{g}\right), R T s$, and error rate. As Table 3 shows, the group analysis followed the same pattern as the individual analysis.

\section{DISCUSSION}

Psychophysically, it could be stated that as a result of the immediate prior experience, the subject's perception of lines in a certain specific orientation becomes affected. However, this is generally true of presentations in the LVF. The results indicate that the right hemisphere is more readily affected by selective adaptation than is the left. This would seem to suggest that the right hemisphere is more sensitive to orientation. It is not immediately apparent how this differential rate of adaptation is related to hemispheric specialization. However, it seems that understanding the basis of hemispheric specialization will entail gaining an insight into the characteristics of the basic underlying units. The results of this study are a step in that direction.

Table 3

Group Summary Data for Area Under the Iso-Sensitive Curve (Ag), Reaction Time (RT), and Accuracy (Proportion Correct) as a Function of Adapting Duration, Visual Field, and Same vs. Different Pairings (Pair Type)

\begin{tabular}{|c|c|c|c|c|c|}
\hline \multirow[b]{2}{*}{ Field } & \multirow[b]{2}{*}{$\mathrm{Ag}$} & \multicolumn{2}{|c|}{ RT } & \multicolumn{2}{|c|}{ Proportion Correct } \\
\hline & & Same & Different & Same & Different \\
\hline & \multicolumn{5}{|c|}{$5,000-M s e c$ Condition } \\
\hline LVF & .67 & 1639 & 1577 & .56 & .67 \\
\hline \multirow[t]{2}{*}{ RVF } & .90 & 1255 & 1168 & .88 & .83 \\
\hline & \multicolumn{5}{|c|}{$1,000-M \sec$ Condition } \\
\hline \multirow{3}{*}{$\begin{array}{l}\text { LVF } \\
\text { RVF }\end{array}$} & .85 & 1264 & 1160 & .66 & .83 \\
\hline & .92 & 1131 & 1105 & .83 & .89 \\
\hline & \multicolumn{5}{|c|}{ 500-Msec Condition } \\
\hline LVF & .87 & 1291 & 1127 & .73 & .84 \\
\hline RVF & .89 & 1263 & 1084 & .70 & .94 \\
\hline
\end{tabular}




\section{REFERENCES}

Blakemore, C., \& Campbell, F. W. On the existence of neurones in the human visual system selectively sensitive to the orientation and size of retinal images. Journal of Physiology, 1969, 203, 237-260.

Campbell, F. W., Cleland, B. G., Cooper, G. F., \& Enroth* Cugent, C. The angular selectivity of visual cortical cells to moving gratings. Journal of Physiology, 1968, 198, 237-250.

Camprell, F. W., \& Kulikowski, J. J. Orientation selectivity of the human visual system. Journal of Physiology, 1966, 187, 437-445.

Davison, T. C. B., \& JAGACinsk ı, R. J. Nonparametric analysis of signal detection confidence ratings. Behavior Research Methods \& Instrumentation, 1977, 9, 545-546.

De Renzi, E., Faglioni, P. L., \& Scotti, G. Judgements of spatial orientation in patients with focal brain damage. Journal of Neurology, Neurosurgery \& Psychiatry, 1971, 34, 489-495.

Fidell, L. S. Orientation specificity in chromatic adaptation of human "edge-detectors." Perception \& Psvchophysics, 1970 , 8, 235-237.

Gilinski, A. S., \& Cohen, H. H. Reaction time to change in visual orientation. Perception \& Psychophysics, 1972, 11, 129-134.

Hubel, D. H., \& Wiesel, T. N. Receptive fields, binocular interaction and functional architecture in the cat's visual cortex. Journal of Physiology, 1962, 160, 106-154.

Hubel, D. H., \& Wiesel, T. N. Receptive fields and functional architecture in two non-striate visual areas (18 and 19) of the cat. Journal of Neurophysiology, 1965, 28, 229-289.

HubEL, D. H., \& WiESEl, T. N. Receptive fields and functional architecture of monkey striate cortex. Journal of Physiology, $1968,195,215-243$.

Levy, J., Trevarthen, C. B., \& Sperry, R. W. Perception of bilateral chimeric figures following hemispheric deconnection. Brain, 1972, 95, 61-78.

McCollough, C. Color adaptation of edge-detectors in the human visual system. Science, 1965, 149, 1115-1116.

Milner, B. Interhemispheric differences in the localization of psychological processes in man. British Medical Bulletin, 1971, 27, 272-277.

Nerts, R. D. Superiority of the minor hemisphere in commissurotomized man for the perception of part-whole relations. Cortex, 1971, 7, 333-347.

Nebes, R. D. Dominance of the minor hemisphere in commissurotomized man in a test of figural unification. Brain, 1972, 95, 633-638.

Nebes, R. D. Hemispheric specialization in commissurotomized man. Psychological Bulletin, 1974, 81, 1-14.

Sperry, R. W. Mental unity following surgical disconnection of the cerebral hemispheres. Harvey Lectures, 1968, 62, 293-323.

Sperry, R. W., \& Gazzaniga, M. S. Language following surgical disconnection of the commissures. In F. L. Darley (Ed.), Brain mechanisms underlying speech and language. New York: Grune \& Stratton, 1967.

Warrington, E. K., \& Rabin, P. Perceptual matching in patients with cerebral lesions. Neuropsychologia, 1970, 8, 475-487.

Weinstein, N. What the frog's eye tells the human brain: Single cell analyzers in the human visual system. Psychological Bulletin, 1969, 72, 157-176.

Zaidel, D., \& Sperry, R. W. Performance on the Raven's Coloured Progressive Matrices by subjects with cerebral commissurotomy. Cortex, 1973, 9, 34-39.

\section{NOTE}

1. With respect to accuracy of performance, we were mainly concerned with the overall performance on left visual field presentations as opposed to right visual field presentations. The interest was in the overall LD effects and not in the "same" and "different" responses. Hence, we looked at total number of errors committed on left visual field presentations as opposed to right visual field presentations, regardless of the type of judgment involved.

(Received for publication March 3, 1980; revision accepted August 29, 1980.) 